\title{
Effective Music Sight-Reading Training Strategies Target Visual Working Memory
}

\author{
Jue Zhou' ${ }^{1}$, Ying Zhong' ${ }^{2}$ Ye Bai ${ }^{1}$ \\ ${ }^{1}$ College of Arts, Chongqing University, Chongqing, China \\ ${ }^{2}$ School of Music, Southwest University, Chongqing, China \\ Email: zhoujue97@cqu.edu.cn
}

Received 28 December 2015; accepted 23 January 2016; published 26 January 2016

Copyright (C) 2016 by authors and Scientific Research Publishing Inc.

This work is licensed under the Creative Commons Attribution International License (CC BY).

http://creativecommons.org/licenses/by/4.0/

(c) (i) Open Access

\section{Abstract}

Sight reading is a functional skill which is essential for all musicians involved in particular fields of classical music culture. Reviewing the achievements from empirical science, this article investigates Visual Spatial Sketchpad (an essential part of working memory) during the process of sightreading, and tries to decipher its mechanism by categorizing the information types of music sheet. After analyzing, we provide two models to explain the different performing styles between novice and expert: Hierarchical Progressive Model and Parallel Dispose Model, which pinpoint Selective Attention as the key element of sight-reading process. Finally, two target training strategies are tentatively proposed: Visual Searching Template Training and Automated Binding Training. If we compose specific training materials by adopting these two strategies, it would be promising that the speed at which students can master sight-reading skills will be increased.

\section{Keywords}

Music Sight-Reading, Working Memory, Selective Attention Models, Training Strategies

\section{Introduction}

Visual Spatial Sketchpad (VSS), also known as Visual Working Memory (VWM), is an essential part of human's working memory which is responsible for generating, operating and storing visual images. According to cognitive psychology, VSS can be divided into two sub-systems which are Visual-object Working Memory and Visual-spatial Working Memory. A large number of experiments suggested that Visual-object Working Memory is in charge of storing and processing features of objects, such as shape, color and size. On the other hand, Visualspatial Working Memory is in charge of storing and processing features of spatial location, movement etc. (De Renzi \& Nichelli, 1975; Farah et al., 1988; Hanley, 1991; Tresch et al., 1993; Grossi et al., 1993; Della, 1999; 
Klauer \& Zhao, 2004.; Darling, 2006). As VSS plays a very important role in piano sight-reading progress, this article will try to explain and analyze the mechanism of VSS in piano sight-reading, from which we can propose targeted strategies for piano educators/students.

This article investigates VSS during the process of sight-reading, and categorizes the information types of music sheet. After analyzing, Hierarchical Progressive Model and Parallel Dispose Model are provided to explain the different performing styles between novice and expert, which pinpoint selective attention as the key element of sight-reading process. Finally, two target training strategies are tentatively proposed: Visual Searching Template Training and Automated Binding Training.

\section{The Division of VSS: Evidence from Empirical Science}

\subsection{The Awareness of VSS Division}

The phenomenon of VSS Division was first discovered by neuroscientists. De Renzi and Nichelli (1975) had learned that patients with impaired cerebral right hemisphere got low scores in spatial memory span task, but their scores on space perception and spatial long time memory are equal to average people; Farah et al. (1988) had found that some patients with brain injuries could point out position changes or movements of an object but failed to identify the shape, size or color of the same object, while other patients could recognize the shape, size or color of an object, but failed to realize the object was in different position; Grossi et al. (1993) came to the same conclusion in a research towards 39 patients with Alzheimer's disease. Therefore, the neuroscientists proposed that visual-object information and visual-spatial information were received and stored in separated neural system of human brain.

\subsection{Recently Development}

In the past twenty years, with the rapid development of brain cognitive imaging technology, many advanced techniques such as ERP (event related potential), PET (positron emission computerized tomography) and FMRI (Functional magnetic resonance imaging) have been used in the researches concerning human brain activation mechanism of various VSS types. Smith and Jonides (1999) have found that visual-spatial working memory activate the right hemisphere of the brain, including right posterior cortex, right occipital cortex, right frontal excitable area and right ventral lateral prefrontal cortex, while the visual-object working memory activate the left posterior cortex, left frontal excitable area and inferior temporal lobe; Wo, Lin, and Luo (2005) use ERP to investigate the brain activation site and found that visual-spatial working memory induced NSW (negative slow wave), which is the typical feedback of psychological resource investment, much earlier than visual-object working memory; Mecklinger and Pfeifer's research (1996) found that the NSW received from the left prefrontal lobe and temporal lobe in visual-object working memory task was much larger than the one in visual-spatial working memory, as the left prefrontal lobe and temporal lobe were in charge of speech rehearsal. He assumed that voice coding had participated in visual-object working memory but not in visual-spatial working memory. This assumption was supported by the experiment of Luo et al. (2006).

\section{The Key Point of Sight-Reading}

\subsection{Selective Attention in Sight Reading}

From my point of view, piano sight-reading works as a zoom lens, and piano novice's attention all focuses on mixed information-music note because that's the basic information of the sheet. With the development of sightreading capacity, their focal point gradually enlarged to cover action information, then finally semantic information. It explains why a piano novice can barely notice other information on music sheet other than music note but experts can express almost every detail of the sheet, even the emotions behind the sheet. The valve which controls the zoom lens is what we call "Selective Attention", a key point of sight-reading training.

Selective Attention is a psychological term of attention which means we center our attention on certain important elements of our environment while other things are blend into the background or pass us by completely unnoticed. Selective Attention includes two facets: choosing relative information and restraining irrelevant elements. To piano novice, they are not familiar with the corresponding positions of music notes on the keyboard, so the main problem for them is deciphering the relationship between notes and keyboard while other informa- 
tion such as expressional marks, strength marks and even fingering are restrained as irrelevant elements; Piano experts are very familiar with the notes and keyboard, they can automatically find the position on the keyboard once they look at a note. This automation saves their psychological energy, so they can pay attention to action information and semantic information.

\subsection{Different SA Models in Sight Reading}

The selective attention of piano novice is a hierarchical progressive model which follows a routine: mixed information $\rightarrow$ action information $\rightarrow$ sematic information. Only after they finished upper level information can their attention notice the second one. If the upper level of information costs too much psychological energy, their attention will restrain information from the lower level to make sure the upper level information is well processed, so novice can barely notice the existence of other information. On the contrary, piano experts' selective attention is a parallel dispose model. Their psychological energy could equally fall to all kinds of information. The better they sight-read, the more energy fastens on sematic information. In that case, they can play all the explicit information of the music sheet very well while at the same time expressing the implicit information behind the sheet which comes from their experience or from their long term memory knowledge. The different type of selective attention model of piano novice and experts are list as Figure 1 and Figure 2.

Compare the two models we can see very clearly that the different types of selective attention caused different sight-reading speeds. This huge difference instructs that selective attention is the key point of piano sight-reading. If we want to renovate students' VSS, we should try to optimize their selective attention and focus on teaching them how to associate body movements with certain music clusters or automatize musical information.

\section{The Strategies of VSS Innovation}

As analysis above, the main concern about VSS innovation is automation. The concept "Automation” as a psychology term means a high effective mental process without any purpose, any consumption of cognitive resources and any conscious. Sight-reading belongs to creative work which costs large amount of cognitive resources. However, automation in sight-reading can save one's psychological energy by binding information

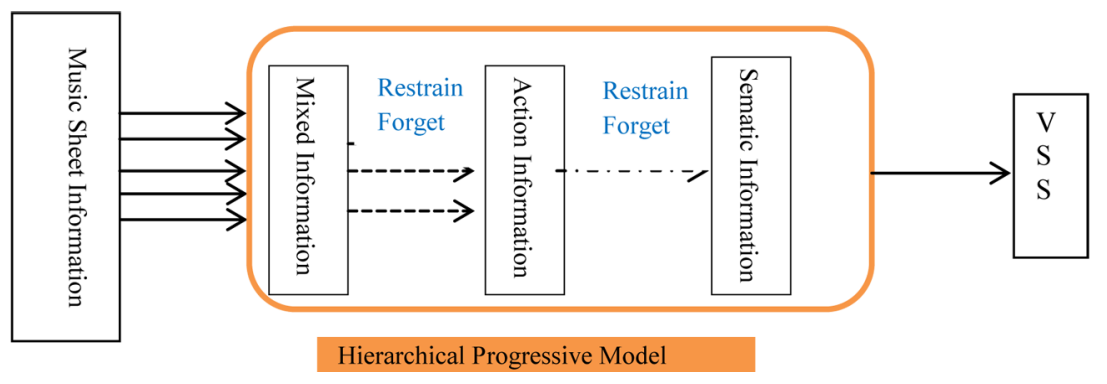

Figure 1. Selective attention model of novice.

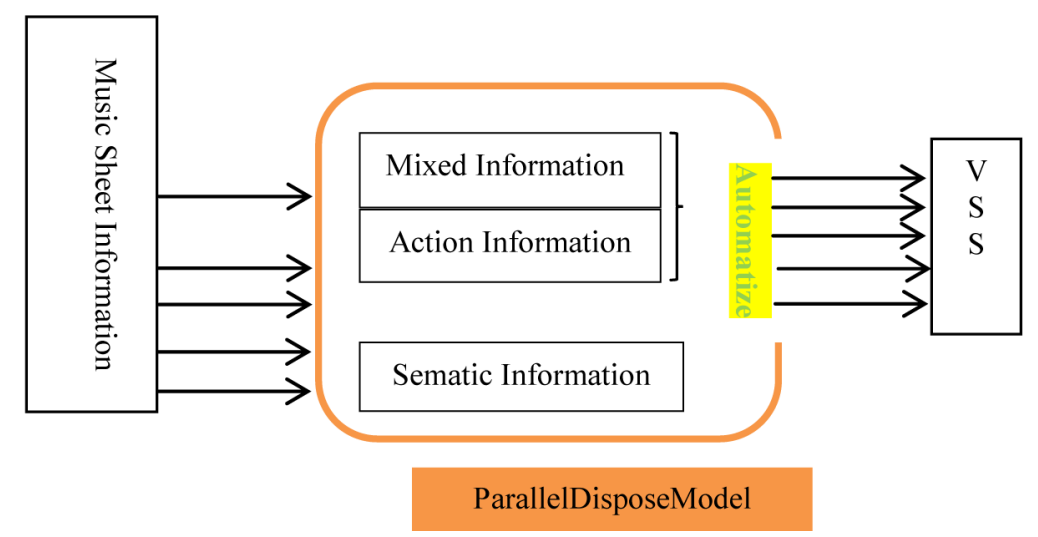

Figure 2. Selective attention model of experts. 
which doesn't need much attention. As shown in the diagrams above, piano experts can process mixed information and action information from music sheet automatically. This automation is the consequence of long time practice through years, which means their capability of binding information is a spontaneous development without conscious control. Our purpose of sight-reading training is to turn unconscious into conscious and make the long period of spontaneous exploration shorter. So, how can we realize automation in piano sight-reading?

Based on analysis before, I propose two strategies for piano sight-reading training: Visual Searching Template Training and Automated Binding Training.

\subsection{Visual Searching Template Training: Target Strategy towards Visual-Object WM}

Template is the figure or characteristic representation of information or objects which are stored in visual-object WM. Studies from cognitive psychology suggest that objects which match the template completely can earn more attention while at the same time the template can give the objects with more semantic associations (Duncan \& Humphreys, 1989; Bundesen, 1990; Desimone \& Duncan, 1995) Serials of physiologic studies on primates came to the same conclusion (Chelazzi, 1993; 1998; 2001). The empirical discoveries indicate that the existence of template will greatly improve the working efficiency of VSS.

According to my analysis, the template we need in piano sight-reading is "Visual Searching Template". Visual searching is a cognitive activity which abstracts target features of objects from complex environment. The visual searching template in piano sight-reading is a database of typical music clusters. Here is an example:

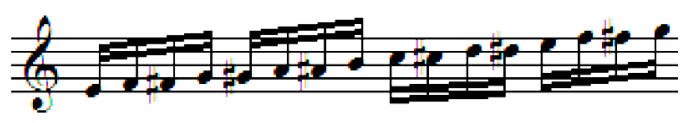

This is a piece of piano sheet. Experts may find it is quite easy but to novice it is difficult, because there are so many temporary marks between a serial of semiquavers. Novice would probably identify the singing name of each note before they can play on piano. The visual searching template we should offer to the novice is marked with red circles as below:

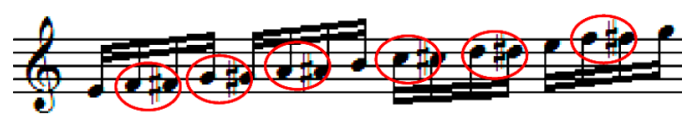

We should also conclude the template as: 1) Adjacent notes in same position; 2) A series of temporal marks. With the knowledge of this visual searching template, novice can easily identify this piece as a chromatic scale. And with automated binding training, which I will discuss later, novice can sight-read this piece faster.

In visual searching template training, we should provide piano novice with templates "database" which abstract all typical music clusters. From the database, novices learn how to process music as chunked information instead of independent single notes. As educational psychology studies have already proved that chunking cognition of study materials can dramatically improve study achievement (Ahissar \& Hochestein, 1997; Chun \& Jiang, 1998; Sigma \& Gilbert, 2000; Sireteanu \& Rettenbach, 2002), we assume that novice’s sight-reading speed can be accelerated as well.

\subsection{Automated Binding Training: Target Strategy towards Visual-Spatial WM}

Based on the template database, my second training strategy focuses on binding fingers or even body movements with music clusters. Take the chromatic scale mentioned before for instance. We could ask students to use middle fingers for black keys while use thumbs and index fingers for white keys regularly. With repeat practice students can automatically binding fingering with chromatic scales. In that case, they can just glance the first note and last one to make sure of the starting point and destination instead of sight-read every note in that scale. With no doubt this strategy would improve their sight-reading speed dramatically.

The automated binding training is not an unprecedented new method, we can find rudiments of automated binding training in textbooks such as Hanon finger exercises and Schmitt finger exercises; however, previous exercises neglect reinforcement of intensive training under conscious control. As mentioned before, lots of piano students' sight-reading capacities develop spontaneously through years of practice, which means Students may 
sum up experiences from random exercises but barely realized the connection between movements and music notes, not to say use movements to guide sight-reading. For automated binding training, we should compose scientific and systematic exercises that targeted cognitive trait of students, and teach them how to manipulate finger movements consciously to indicate templates. In that case, they can achieve automation in sight-reading much sooner.

\section{Conclusion}

In this article, we analyzed the mechanism of Visual Spatial Sketchpad in piano sight-reading based on empirical studies and provided some models to explain the cognitive process of VSS. After pinpointing selective attention as the key element of sight-reading, we tentatively propose two target training strategies: Visual Searching Template Training and Automated Binding Training. If we compose specific training materials by adopting these two strategies, it would be very promising that the speed at which students can master sight-reading skills will be greatly increased.

\section{References}

Ahissar, M., \& Hochstein, S. (1997). Task Difficult and the Specificity of Perceptual Learning. Nature, 387, 401-406. http://dx.doi.org/10.1038/387401a0

Bundesen, C. (1990). A Theory of Visual Attention. Psychological Review, 97, 523-547. http://dx.doi.org/10.1037/0033-295X.97.4.523

Chelazzi, L., Miller, E. K., \& Duncan, J. (1993). A Neural Basis for Visual Search in Inferior Temporal Cortex. Nature, 363, 345-347. http://dx.doi.org/10.1038/363345a0

Chelazzi, L., Duncan, J., \& Miller, E. K. (1998). Responses of Neurons in Inferior Temporal Cortex, during Memory-Guided Visual Search. Journal of Neurophysiology, 80, 2918-2940.

Chun, M. M., \& Jiang, Y. (1998). Contextual Cueing: Implicit Learning and Memory of Visual Context Guides Spatial Attention. Cognitive Psychology, 36, 28-71. http://dx.doi.org/10.1006/cogp.1998.0681

Darling, S., Della, S., Logie, R., \& Cantagallo, A. (2006). Neuropsychological Evidence for Separating Components of Visuo-Spatial Working Memory. Journal of Neurology, 253, 176-180. http://dx.doi.org/10.1007/s00415-005-0944-3

De Renzi, E., \& Nichelli, P. (1975). Verbal and Non-Verbal Short-Term Memory Impairment Following Hemispheric Damage. Cortex, 11, 341-354. http://dx.doi.org/10.1016/S0010-9452(75)80026-8

Della, S., Gray, C., Baddeley, A., Allamano, N., \& Wilson, L. (1999). Pattern Span: A Tool for Unwelding Visuo-Spatial Memory. Neuropsychologia, 37, 1189-1199. http://dx.doi.org/10.1016/S0028-3932(98)00159-6

Desmone, R., \& Duncan, J. (1995). Neural Mechanisms of Selective Visual Attention. Annual Review of Neuroscience, 18, 193-222. http://dx.doi.org/10.1146/annurev.ne.18.030195.001205

Duncan, J., \& Humphreys, G. W. (1989). Visual Search and Stimulus Similarity. Psychological Review, 96, 433-458. http://dx.doi.org/10.1037/0033-295X.96.3.433

Farah, M. J., Levine, D. N., \& Calvanio, R. (1988). A Case Study of Mental Imagery Deficit. Brain and Cognition, 8, 147164. http://dx.doi.org/10.1016/0278-2626(88)90046-2

Grossi, D., Becker, J. T., Smith, C., \& Trojano, L. (1993). Memory for Visuos-patia Patterns in Alzheimer's Disease. Psychological Medicine, 23, 63-70. http://dx.doi.org/10.1017/S003329170003885X

Klauer, K. C., \& Zhao, Z. (2004). Double Dissociations in Visual and Spatial Short-Term Memory. Journal of Experimental Psychology: General, 13, 355-381. http://dx.doi.org/10.1037/0096-3445.133.3.355

Luo, Liang, Lin, C. D., \& Liu, Z. M. (2006). Effects of Memory Load of Brain Activation in Object Working Memory Task. Journal of Psychology, 38, 805-814.

Mecklinger, A., \& Pfeifer, E. (1996). Event Related Potentials Reveal Topographical-Spatial Visual Working Memory Activate Separate Neural Systems in Spatial and Object Working Memory. Cognitive Brain Research, 4, 211-224. http://dx.doi.org/10.1016/S0926-6410(96)00034-1

Sigma, M., \& Gilbert, C. (2000). Learning to Find a Shape. Nature Neuroscience, 3, 264-269. http://dx.doi.org/10.1038/72979

Sireteanu, R., \& Rettenbach, R. (2002). Perceptual Learning in Visual Search Generalizes over Tasks, Locations and Eyes. Vision Research, 40, 2925-2949. http://dx.doi.org/10.1016/S0042-6989(00)00145-0

Smith, E., \& Jonides, J. (1999). Storage and Executive Processes in the Frontal Lobes. Science, 283, 1657-1661. http://dx.doi.org/10.1126/science.283.5408.1657 
Tresch, M. C., Sinnamon, H. M., \& Seamon, J. G. (1993). Double Dissociation of Spatial and Object Visual Memory: Evidence from Selective Interference in Intact Human Subjects. Neuropsychologia, 31, 211-219.

http://dx.doi.org/10.1016/0028-3932(93)90085-E

Wo, J. Z., Luo, L., \& Lin, C. D. (2005). The Division of Object Working Memory and Spatial Working Memory: Evidence from SCP. Journal of Psychology, 37, 729-738. 